\title{
Avaliação de manifestações patológicas em fachadas: Estudo de caso em edifícios residenciais em Salvador/BA.
}

\author{
COSTA, P. Z. ; FREITAS, P. V. G' ${ }^{2}$; A. R. A. OMORE ${ }^{3}$, M. A. MACHADO ${ }^{3 *}$; V. A. COELHO ${ }^{4 ;}$ \\ SILVA, F. G. S . \\ *Autor de contato: marina.machado@,outlook.com

\footnotetext{
${ }^{1}$ Pós-graduando em Engenharia de Avaliação e Perícia, Universidade Jorge Amado, Salvador, Brasil

${ }^{2}$ Área de Construção Civil, SENAI CIMATEC, Salvador, Brasil

${ }^{4}$ PPEC, Escola Politécnica, Universidade Federal da Bahia, Salvador, Brasil

${ }^{5}$ Departamento de Construção e Estruturas, Universidade Federal da Bahia, Salvador- Ba, Brasil
} \\ ${ }^{3}$ Graduado(a) em Engenharia Civil, Escola Politécnica, Universidade Federal da Bahia, Salvador, Brasil
}

\begin{abstract}
RESUMO
Fachada é um dos principais sistemas de uma edificação que além da estética, visa protege-la das intempéries, aumentando seu desempenho e vida útil. Apesar de sua relevância, o revestimento de fachada tem sido executado sem os devidos cuidados técnicos, gerando grande número de anomalias. Este artigo tem por finalidade demonstrar variadas manifestações patológicas existentes em fachadas constituídas por revestimento cerâmicos e pintura sobre reboco em edifícios residenciais da cidade de Salvador. Para isto, a metodologia utilizada foi: a) Vistoria in loco; b) coleta de dados, c) Ensaios não destrutivos d) Catalogação de anomalias e e) Proposições de terapias. Essa pesquisa levou à conclusão de como essas anomalias interferem diretamente na estética da edificação e favorecem a deterioração do edifício mais rapidamente.
\end{abstract}

Palabras clave: Fachada, Manifestações patológicas; Revestimento. 


\begin{abstract}
Facade is one of the main systems of a building that, in addition to aesthetics, aims to protect it from the elements, increasing their performance and service life. Despite its relevance, the façade cladding has been carried out without due technical care, generating a large number of anomalies. The purpose of this article is to demonstrate various pathological manifestations existing in facades made up of ceramic coating and painting on plaster in residential buildings in the city of Salvador. For this, the methodology used was: a) On-site inspection; b) data collection, c) Nondestructive testing d) Cataloged of anomalies and e) Therapy proposals. This research led to the conclusion that these anomalies directly interfere in the building's aesthetics and favor the building's deterioration more quickly.
\end{abstract}

Keywords: Facade, pathological manifestations; Coating.

\title{
RESUMEN
}

La fachada es uno de los principales sistemas de un edificio que, además de la estética, tiene como objetivo protegerlo de los elementos, aumentando su rendimiento y vida útil. A pesar de su relevancia, el revestimiento de la fachada se ha realizado sin los debidos cuidados tecnicos, generando un gran número de anomalías. El propósito de este artículo es demostrar as manifestaciones patologícas en la fachadas existentes en revestimiento cerámico y pintura sobre yeso en edificios residenciales de la ciudad de Salvador. Para ello, la metodología utilizada fue: a) Inspección in situ; b) recogida de datos, c) Ensayos no destructivos d) Catalogación de anomalías y e) Propuestas terapéuticas. Esta investigación llevó a la conclusión de cómo estas anomalías interfieren directamente en la estética del edificio y favorecen el deterioro de esta con mayor rapidez.

Palabra Clave: Fachada, pathological manifestations; Revestimiento . 


\section{INTRODUÇÃO}

A área de revestimento externo de uma edificação, a qual chamamos Fachada, apresenta importantes funções, dentre elas a de proteger os elementos de vedação dos edifícios da ação direta dos agentes agressivos como vento, intempéries, é o isolamento termo acústico, e serve também de substrato regular para recebimento de elementos de decoração tais como cerâmicas, rocha e pintura. Além disso, os revestimentos também cumprem a função estética, contribuindo significativamente para a valorização do imóvel. (GALLETTO; ANDRELLO, 2013).

As especificações de projeto para o preparo da base que receberá os revestimentos, assim como o controle dos materiais constituintes aliada a uma mão-de-obra bem treinada, devem ser observadas e controladas para que se evite futuramente o aparecimento de fissuras ou qualquer outra manifestação patológica na fachada. (SILVA, 2005).

As ocorrências das fissuras ou trincas podem ser causadas por retração, variação de temperatura, esforços mecânicos, recalques de fundação, movimentação higroscópica, dentre outras. No que tange a esta ocorrência:

As fissuras podem ser ocasionadas pela retração da argamassa ou concreto, ausência de cura, o uso de areia inadequada ou contaminada, tempo insuficiente de hidratação da cal, falta de juntas de dilatação ou, ainda, movimentações que absorvam a deformidade da estrutura (VERÇOZA, 1991, p. 53).

As manifestações patológicas, são comumente encontradas, com maior frequência, nas fachadas das edificações. Este revestimento externo exerce a função de proteger o edifício frente a ações do ambiente, deste modo, tal aspecto deve ter suas propriedades conservadas, ou no mínimo, existir a possibilidade de substituir ou manutenir mais facilmente, levando em conta o desempenho da vida útil da construção (SILVA, et al., 2011).

Em Salvador, o uso indiscriminado e sem estudo de traços adequados do agregado argilo-mineral comumente chamado de Arenoso, também pode ser a causa de fissuras por retração. Afinal, a presença de finos aumenta a retenção da água, aumentando a área total de contato das partículas com a água, além de reduzir espaços internos na mistura, dificultando a remoção da água. Dessa forma, quanto maior o teor de finos, mais lenta a perda de água com o tempo, maior a reatividade da água com os componentes, e menor água disponível para evaporação, resultando na retração. (PEREIRA,2007)

Em fachadas com revestimentos cerâmicos, a patologia geralmente se manifesta como descolamento da cerâmica, e isso pode estar relacionado a execução por mão de obra não treinada/qualificada; contaminação do substrato (reboco) ou do tardoz da cerâmica; infiltrações nas alvenarias; uso de materiais e ferramentas sem qualidade; falta de juntas de movimentação, dentre outros.

Em geral as causas que levam ao aparecimento de manifestações patológicas, sem sempre são de fácil determinação e podem estar relacionada a mais de um fator causal. Diante disso, o objetivo deste trabalho é analisar as manifestações patológicas observadas em dois edifícios do localizados no bairro de São Marcos, na cidade de Salvador- BA. 


\section{METODOLOGIA}

Para o desenvolvimento do presente trabalho foi realizado visita ao Edifício 1 e Edifício 2, ambos no Bairro de São Marcos, Salvador-BA.

A metodologia deste trabalho consistiu em:

a. Visita técnica às duas edificações;

b. Realização de inspeção visual e levantamento fotográfico das manifestações patológicas encontradas;

c. Realização de termografia infravermelho (máquina FLIR C2);

d. Análise das manifestações patológicas;

e. Proposição de soluções terapêuticas para correção das patologias encontradas.

$\mathrm{Na}$ vistoria foram verificadas e levantadas todas as ocorrências de manifestações patológicas nas fachadas. Foram identificadas a tipologia da estrutura, suas características, localização em relação à incidência solar, ventos e chuvas e o tipo de acabamento.

São edifícios residenciais que apresenta padrão popular, estado de conservação classificado "entre reparos simples e importantes", composto por pavimento térreo e 03 pavimentos superiores, executado em alvenaria estrutural com lajes em concreto armado e cobertura com telhas de fibrocimento.

Os imóveis se encontram em região predominantemente residencial de baixo padrão construtivo, próximo à Avenida São Rafael, uma das principais vias da região, onde se encontram também empreendimentos comerciais, hospital e centros empresariais.

O registro fotográfico permitiu uma avaliação do estado de conservação geral de cada um dos edifícios e uma pré-análise das patologias existentes, assim como as anotações feitas em ficha de registro dos aspectos condição de vizinhança, orientação Solar, sentido das chuvas e também se foi percebido algum tipo de manutenção além da execução de revestimento cerâmico sobre área originalmente pintada. 


\section{ESTUDO DE CASO}

Conforme anotações feitas e do levantamento das principais características das Edificações, notamos que se trata de edifícios de que foram construídos a mais de 25 anos, com finalidade residencial localizados em bairro popular de Salvador, próximo a Av. São Raphael.

\subsection{Estudo de caso edificação - Situação 1}

Na figura 1 está exposta a localização do Edifício 1, situado na cidade de Salvador-BA.

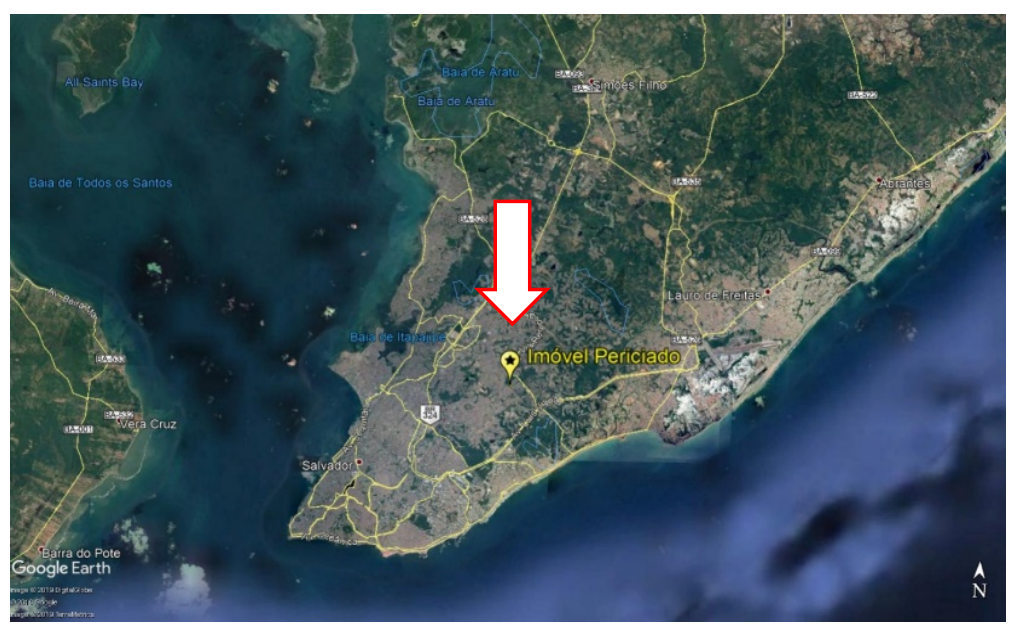

Fonte: Google Earth, 2019

Figura 1 - Localização do Edifício 1

O posicionamento das fachadas é de suma importância para a identificação e análise das ações advindas da natureza, entre elas estão: a orientação solar, a chuva e a incidência e pressão de ventos. Na figura 2 são apresentadas as orientações das fachadas do edifício em questão.

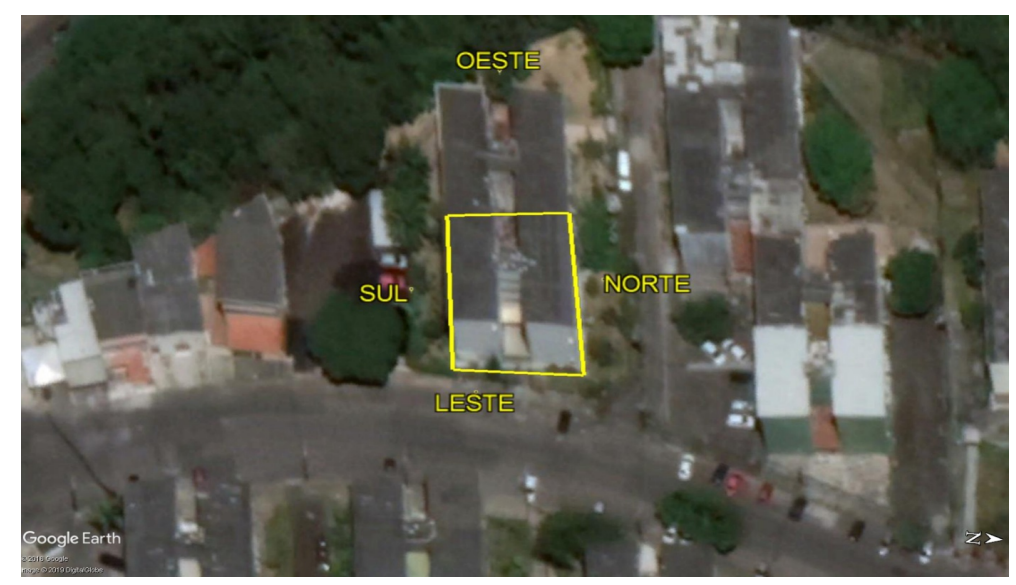

Figura 2. Orientação das Fachadas

Fonte: Google Earth, 2019.

3.1.1 Levantamento da Ocorrência de Patologias 
As fachadas analisadas, caracterizadas como sendo leste, norte e sul, apresentam as seguintes patologias:
a. Desplacamento do Revestimento Cerâmico; (Figura 3)
b. Presença de Fissuras no Revestimento; (Figura 4)
c. Reboco Pulverulento; (Figura 5)
d. Manchas de carbonatação entre as cerâmicas. (Figura 6)

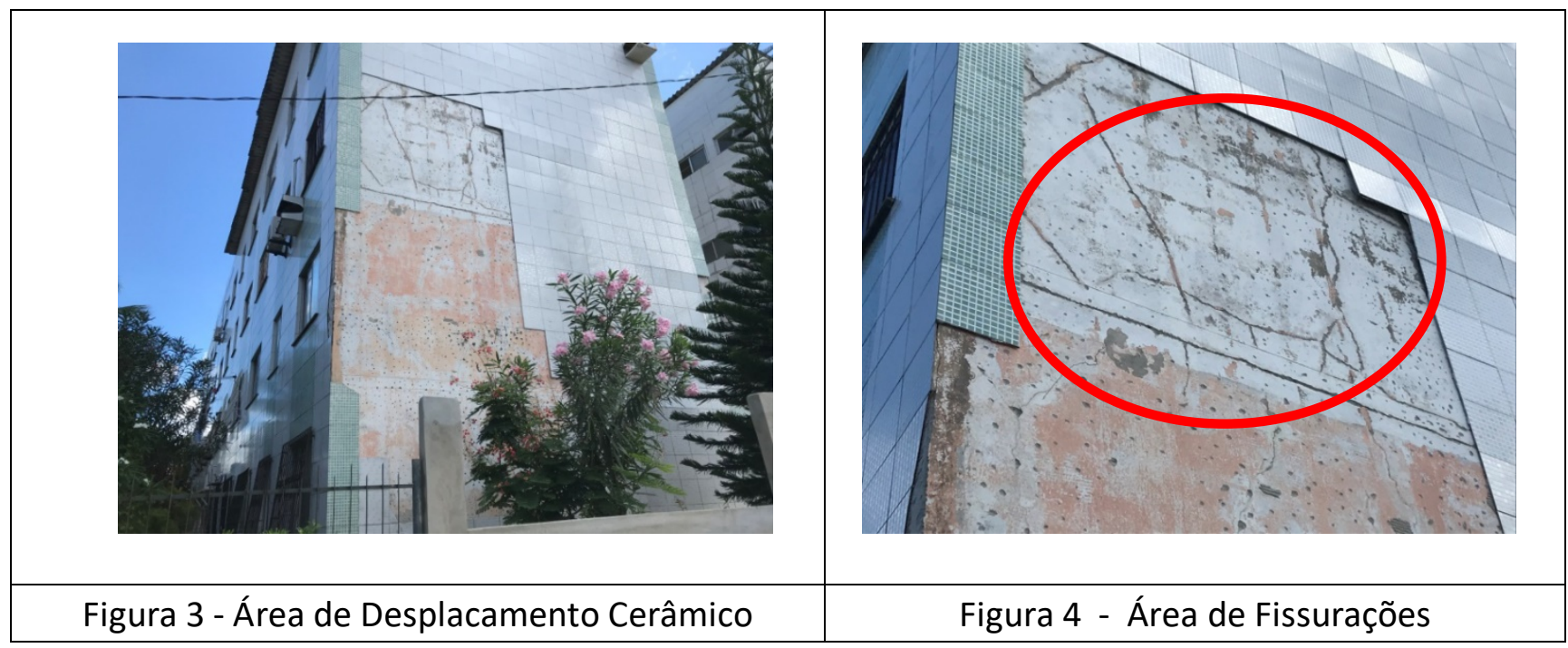

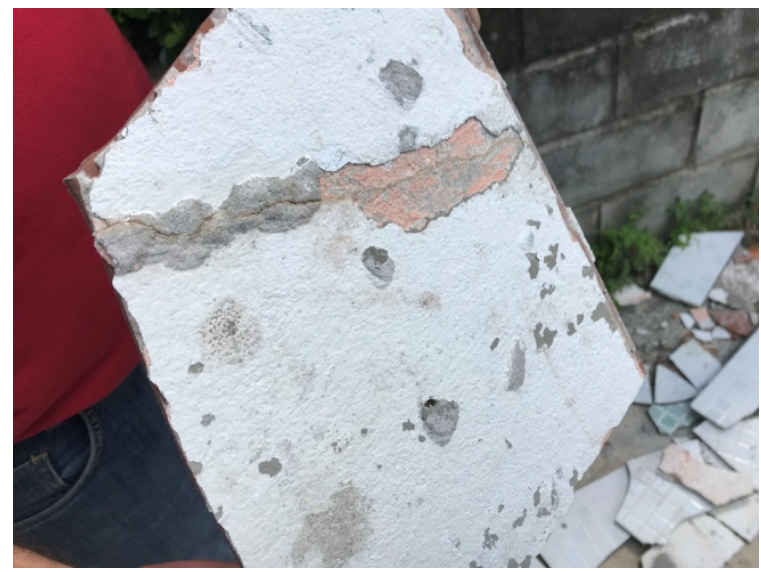

Figura 5 - Reboco Pulverulento

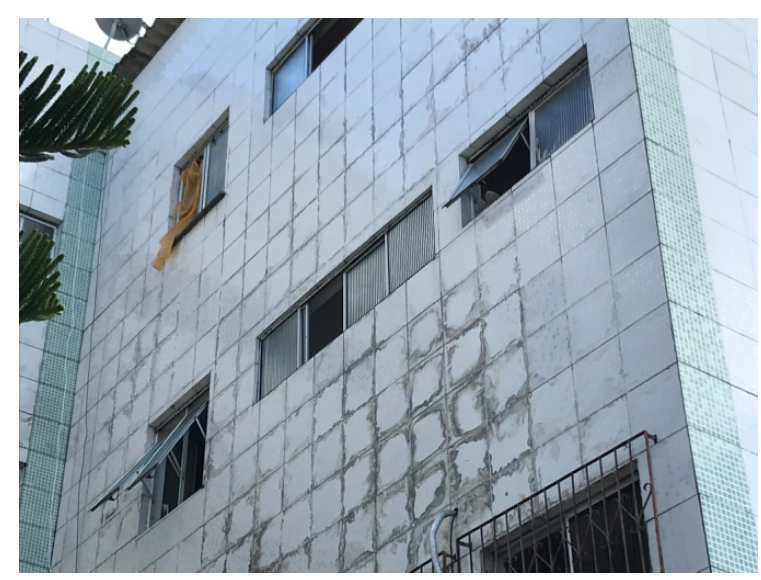

Figura 6 - Carbonatação na área dos rejuntes

\subsubsection{Estado de Conservação do Edifício 1}

a) Influência da condição de exposição das fachadas

Verificou-se que a Fachada Leste apresenta infiltrações ocasionadas por chuva dirigida pelo vento no sentido sudeste. A Fachada Norte apresenta um nível elevado de degradação, o que se deve ao fato de estar voltada para o sentido Noroeste, e, sofrer, portanto, a influência da 
temperatura elevada gerada pela orientação solar. Verifica-se, além do descolamento e desplacamento do revestimento cerâmico, alto índice de retração do revestimento de argamassa.

A Fachada Sul, apesar de estar na zona de influência do vento sudeste, apresenta melhor estado de conservação em relação às demais, por conta da presença de árvores e coqueiros ao longo de sua extensão.

b) Condições de Vizinhança

Em três fachadas não há influência de edificações vizinhas. A fachada norte está distante aproximadamente $14,00 \mathrm{~m}$ do edifício vizinho, que possui a mesma altura do edifício objeto da perícia. No entanto, a fachada sul possui o atenuante da presença de árvores de médio e grande porte na sua proximidade.

c) Condições de execução do sistema

I - Presença de inúmeras fissuras no reboco, por conta da retração da argamassa, provavelmente ocasionadas pela utilização de materiais argilo-minerais na sua composição;

II - Revestimento cerâmico aplicado sobre o reboco, sem a devida retirada do revestimento anterior (pintura), tendo sido este apenas apicoado precariamente, não havendo, portanto, aderência entre a argamassa colante e a argamassa de revestimento das 03 (três) fachadas analisadas;

III - Falha executiva no assentamento da cerâmica, reduzindo a área de aderência da argamassa colante, visto que, verifica-se a existência dos "cordões" de argamassa no fundo das pedras;

IV - Ausência de juntas de movimentação no revestimento cerâmico, havendo o descolamento e desplacamento do revestimento em vários trechos das fachadas;

V - Sinais de Eflorescência entre as cerâmicas devido às falhas no rejuntamento, ocasionando infiltração de água das chuvas direcionadas com influência do vento sudeste, com maior incidência na Fachada Leste.

d) Influência Térmica

Os diversos elementos que compõem as construções estão expostos às variações de temperaturas sazonais e diárias que provocam movimentos de dilatação e contração que, associados às diversas restrições existentes à sua movimentação, como por exemplo a inexistência de juntas, resultam em tensões que segundo Duarte (1998), podem provocar fissuras, chamadas fissuras causadas por movimentação térmica. Como se pode notar no gradiente de temperatura variando mais de $6^{\circ}$ C (Figuras 7 e 8 ). 


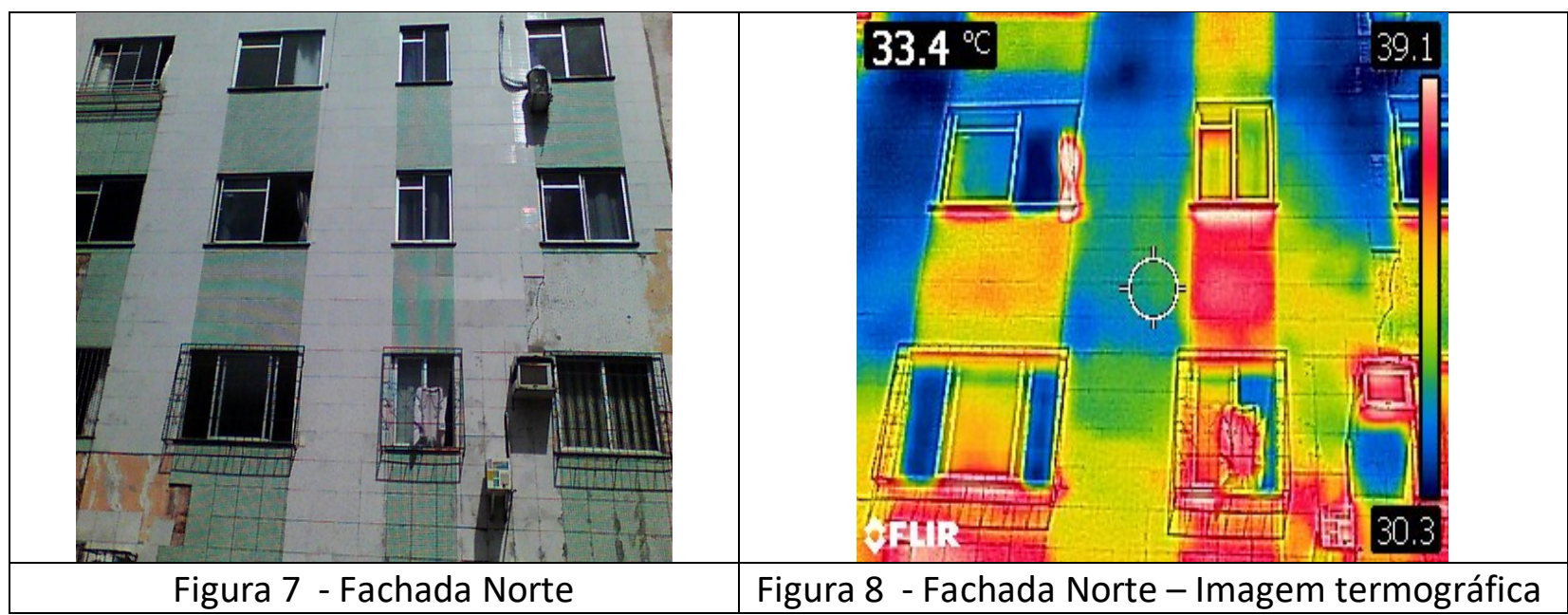

\subsection{Estudo de caso edificação - Situação 2}

Na Figura 9 está exposta a localização do Edifício 2, situado no Conjunto Recanto das Ilhas na cidade de Salvador-BA.

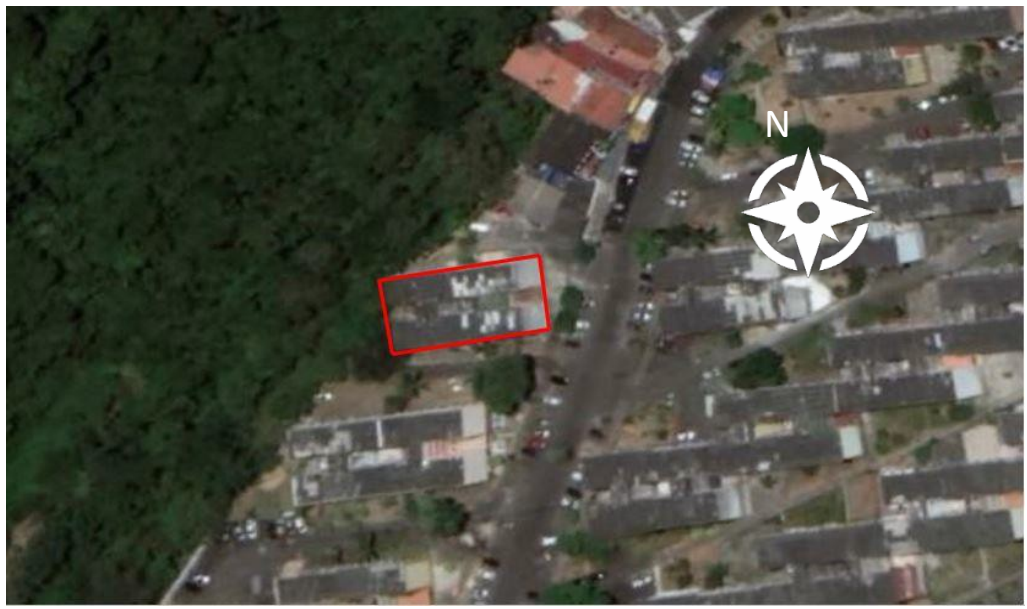

Fonte: Google Earth, 2019

Figura 9 - Orientação das Fachadas

Trata-se de edificação com características semelhantes ao estudo do Edifício llha de Maracá. Estes imóveis se encontram dentro do mesmo Condomínio Conjunto Recanto das Ilhas, em região predominantemente residencial de baixo padrão construtivo, próximo à Avenida São Rafael. Estão distantes um do outro pelo menos setenta metros. Portanto com idades de construção semelhantes e patologias também.

\subsubsection{Levantamento de ocorrência de patologias}

As fachadas analisadas, caracterizadas como sendo leste, norte e sul, apresentam as seguintes patologias:

a. Aplicação de Argamassa Colante sobre Pintura; (Figura 10)

b. Fissuras; (Figura 11)

c. Desplacamento do revestimento cerâmico aplicado; (Figura 12) 


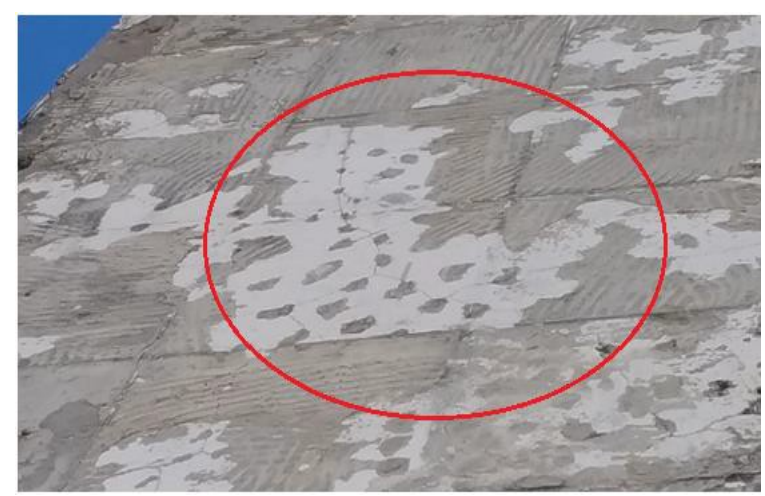

Figura 10 - Argamassa Colante Sobre Pintura

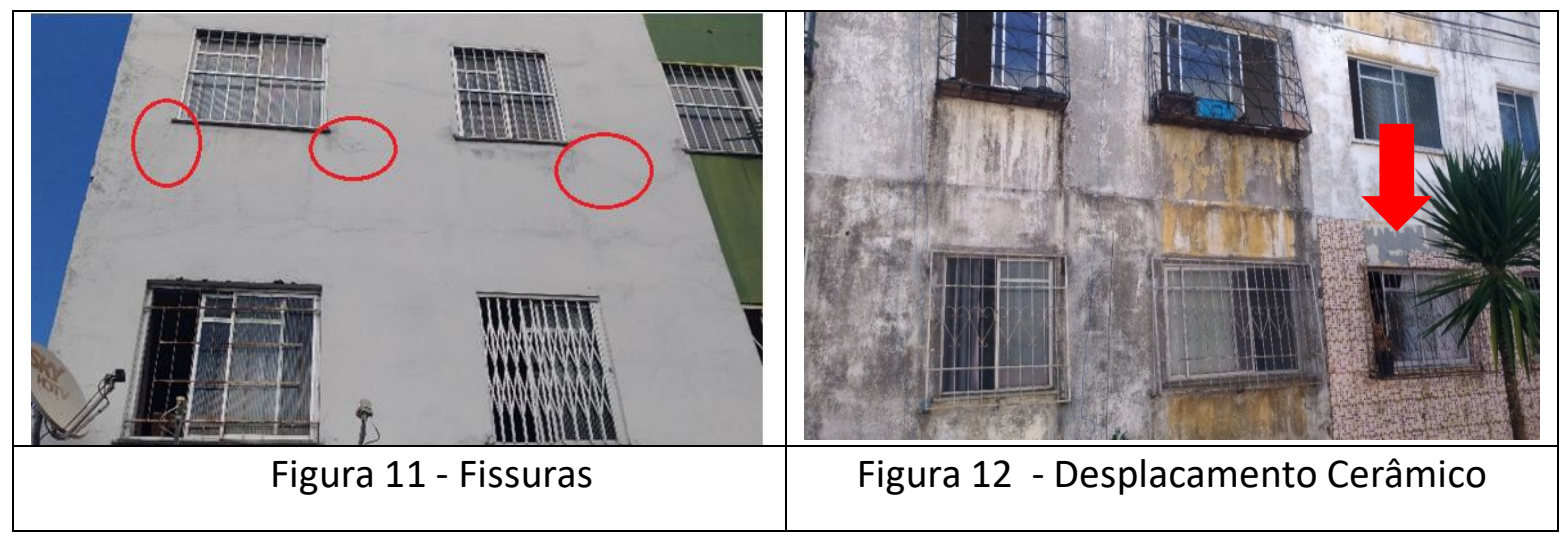

\subsection{Condições de vizinhança}

A Fachada Sudoeste recebe sombreamento do prédio vizinho, bem como de árvores existentes no local, sendo, portanto, a fachada mais úmida, pois junto com a fachada nordeste são as que recebem maior incidência das chuvas.

\subsection{Condições de execução do sistema}

a. Presença de inúmeras fissuras no reboco, por conta da retração da argamassa, provavelmente ocasionadas pela utilização de materiais argilo-minerais na sua composição;

b. Revestimento cerâmico aplicado sobre o reboco, sem a devida retirada do revestimento anterior (pintura), tendo sido este apenas apicoado precariamente, não havendo, portanto, aderência entre a argamassa colante e a argamassa de revestimento onde foi aplicada a cerâmica;

c. Falha executiva no assentamento na Fixação de Grades de Proteção e Aparelhos de Ar Condicionado, facilitando infiltrações, além de fissuras devido a ausência de vergas. (Figura 13). 


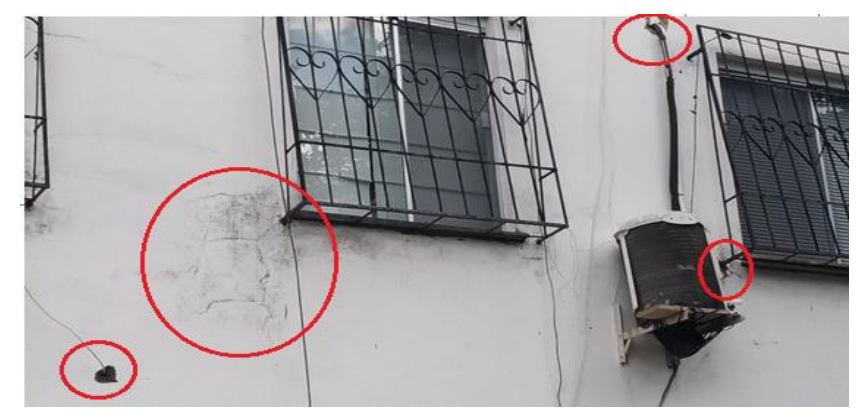

Figura 13. Grades e Ar Condicionado nas Fachadas

\subsection{Influência Térmica}

A Fachada Noroeste é a que mais recebe a incidência dos raios solares e, portanto, encontra-se com a sua pintura desgastada e mais esmaecida que as demais.

\subsection{Avaliação dos edifícios quanto a altitude, ventos, agressividade e distância das bordas marítimas na cidade de salvador}

Ambos os prédios estão no mesmo Bairro e dentro do mesmo condomínio, portanto os índices apurados servem para relativizar os dois estudos de caso. Nos mapas apresentados a seguir teremos as seguintes informações:

\subsubsection{Altitude}

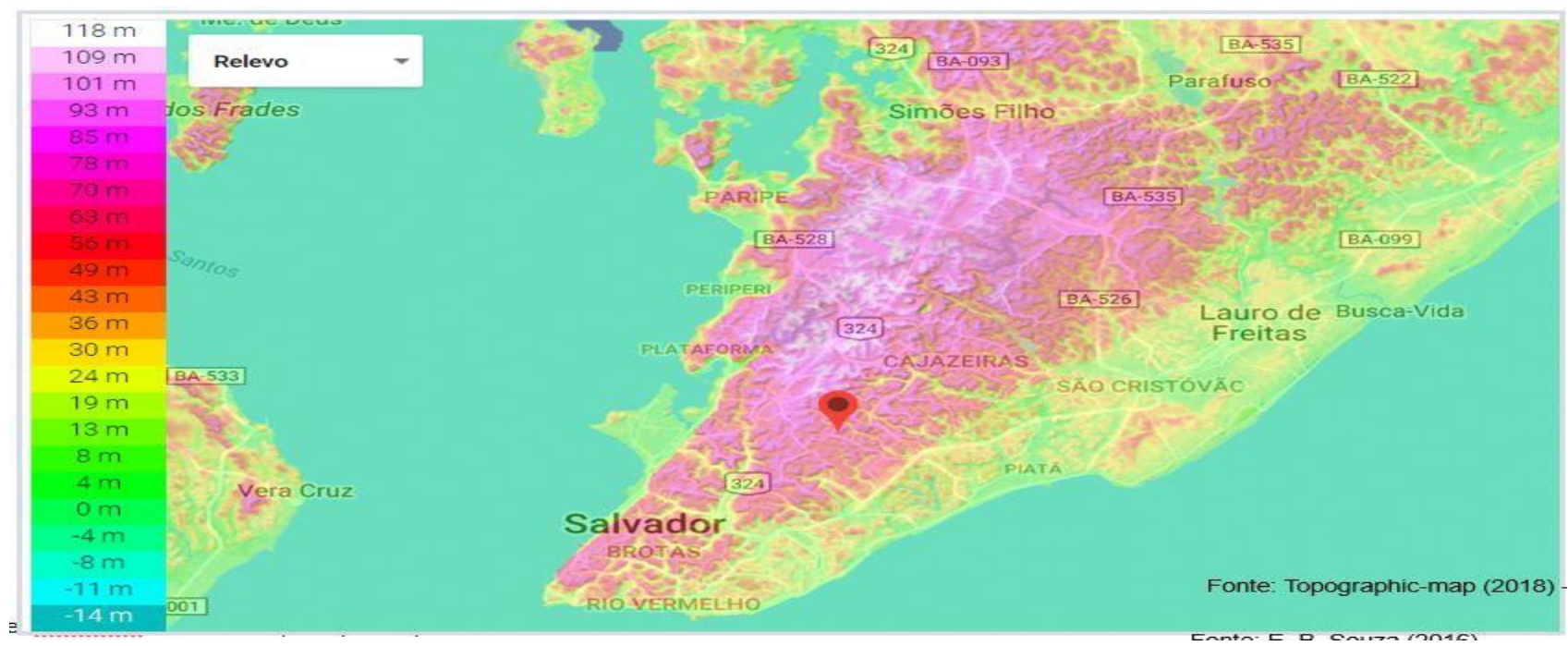

Fonte: Topographic-map, 2018

Figura 14 - Mapa topografico de Salvador

Com base no Mapa Topográfico de Salvador, verifica-se que o Edifício em questão se encontra em região à aproximadamente entre $63 \mathrm{~m}$ e $65 \mathrm{~m}$ de altitude. À Oeste, entre a Orla da Baía de Todos os Santos e o edifício, tem-se uma topografia com níveis mais elevados, chegando à cerca de $109 \mathrm{~m}$ de altitude, o que cria uma espécie de barreira física para os ventos advindos dessa Orla. No entanto, verifica-se que os ventos chegam da predominantemente Orla Atlântica.

3.6.2 Incidência de Ventos 


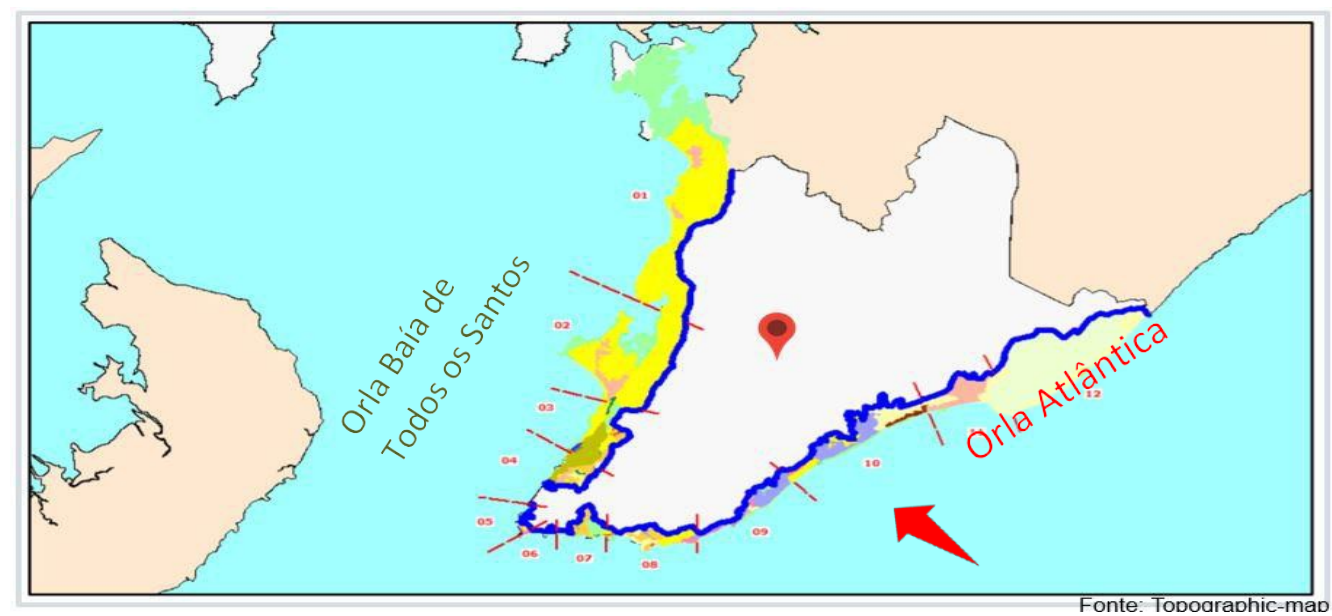

Fonte: Topographic-map, 2018

Figura 15 - Mapa de Incidência de Ventos de Salvador

Com base no Mapa de Incidência dos Ventos de Salvador, verifica-se que os ventos predominantes advindos da Orla Attântica são os Ventos Sudestes.

3.6.3 - Agressividade

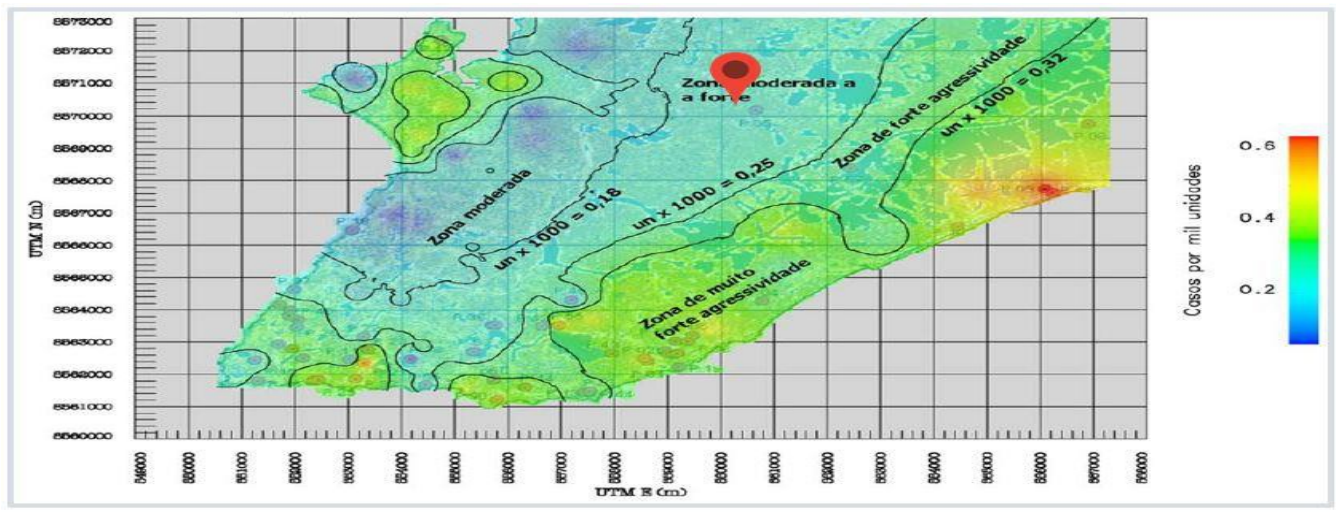

Fonte: Topographic-map, 2018.

Figura 16 - Mapa de Agressividade de Salvador

Segundo o Mapa de Agressividade, verifica-se que os edifícios estão localizados na Zona Moderada a Forte.

3.6.4 - Distância das Bordas Marítimas de Salvador 


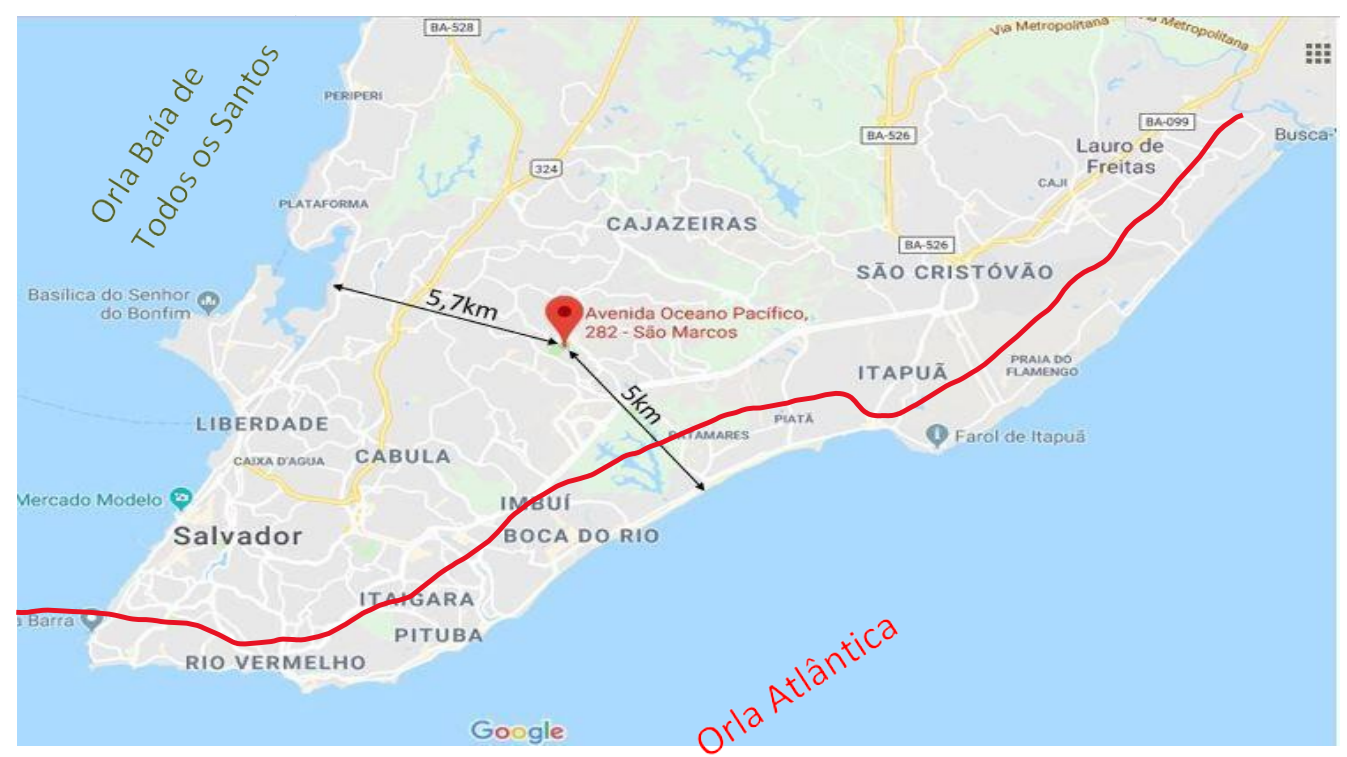

Fonte: Topographic-map, 2018

Figura 17 - Mapa das Bordas Marítimas de Salvador

Ambas localizadas no Bairro São Marcos - Salvador/BA, essas edificações encontram-se à aproximadamente $5,0 \mathrm{~km}$ de distância da Orla Atlântica e à aproximadamente $5,7 \mathrm{~km}$ de distância da Orla da Baía de Todos os Santos. 


\section{RESULTADOS E DISCUSSÕES}

A Presença de inúmeras fissuras no reboco, por conta da retração da argamassa, provavelmente ocasionadas pela utilização de materiais argilo-minerais na sua composição.

Revestimento cerâmico aplicado sobre o reboco, sem a devida retirada do revestimento anterior (pintura), tendo sido este apenas apicoado precariamente, não obtendo, portanto a ponte de aderência necessária para a resistência e durabilidade esperadas.

Falha executiva no assentamento da cerâmica, por mão de obra não treinada e uso incorreto dos das argamassas colantes, reduzindo a sua área de aderência, junto com a ausência de juntas de movimentação no revestimento cerâmico, contribuíram para o desplacamento do revestimento em vários trechos das fachadas.

Manchas de carbonatação entre as cerâmicas devido às falhas no rejuntamento, ocasionando infiltração de água das chuvas direcionadas, associado a adoção de cerâmica com tonalidades diferentes, uma mais clara que a outra, gerando uma diferença de temperatura de mais de $6^{\circ}$ graus Celsius, conforme pode-se verificar nas imagens térmicas, pode ter contribuído para 0 aparecimento das patologias apontadas.

Deve-se relatar também a falha no uso das edificações, tais como, instalações de aparelhos de ar condicionado e gradis em janelas, de maneira a deixar drenos e furos na fachada, o que facilita as infiltrações de agua decorrentes das chuvas.

Essas fachadas necessitam de reparos importantes por conta de suas patologias, ocasionadas pelas ações dos ventos, chuvas e incidência solar, bem como pela falta de manutenção adequada e mau uso, citados anteriormente.

Para a repintura das fachadas, para os trechos revestidos em argamassa, recomenda-se nas fachadas que apresentam maiores deteriorações, o uso de impermeabilizante acrílico sobre a fachada, formando nesta região uma proteção a mais que aumentará a vida útil. De modo geral, devem-se recuperar os trechos com reboco desgastados, assim como todos os pontos possíveis de infiltração provocados pela instalação inadequada de grades, antenas e Aparelhos de Ar condicionado. Após a cura total dessas argamassas, por cerca de 30 dias, aplicar fundo preparador acrílico e depois repintar com tinta a base acrílica.

Para a recuperação da área de revestimento cerâmico, recomenda-se a retirada de todo revestimento existente, assim como a pintura remanescente; tratamento das fissuras; regularização do reboco com a utilização de aditivos que possam melhorar sua aderência; e posterior assentamento da cerâmica com a devida junta de movimentação de acordo com a Normas Técnicas Brasileiras. 


\section{CONCLUSÕES}

Conforme levantamento efetuado, são inúmeras as manifestações patológicas existentes nas edificações, mostrando uma combinação de situações que geraram desde fissurações a desplacamento de revestimento cerâmico. Denota-se que a maior parte das manifestações patológicas das fachadas é originada, principalmente, de imperícias, uso de materiais não controlados e falta de manutenção adequada.

O sistema de revestimento externo das edificações estudadas encontra-se em avançado estado de deterioração, decorrente da falta de projeto, da inexistência de plano de manutenção preventiva, agravado pelo decurso de tempo e pelo uso normal da edificação.

De uma forma geral este trabalho apresentou uma avaliação sobre manifestações patológicas em revestimento de fachadas (argamassa, pintura e cerâmica) e a importância de se conhecer as causas e dessa forma evitar futuras patologias nas fachadas.

Com isso, fica claro a importância da contratação de um bom projeto de fachadas, a correta especificação e aplicação dos materiais, uma mão de obra treinada, em observância as Normas Técnicas e manutenções adequadas e periódicas, visando a maior durabilidade das fachadas. 


\section{REFERÊNCIAS}

ASSOCIAÇÃO BRASILEIRA DE NORMAS TÉCNICAS (2012). NBR 14081: Argamassa colante industrializada para assentamento de placas cerâmicas - Parte 1: Requisitos. Rio de Janeiro.

ABNT - Associação Brasileira de Normas Técnicas. (2017). NBR 13755: Revestimentos de paredes externas e fachadas em com placas cerâmicas e com utilização de argamassa colanteProcedimento. Rio de Janeiro.

CINCOTTO, M.A.(1989). "Patologias das argamassas de revestimento". Publicação IPT/SP 1801. Instituto de Pesquisas Tecnológicas do Estado de São Paulo - IPT, São Paulo, Brasil. p.13p

DUARTE, R. B. (1998). Fissuras em Alvenaria: causas principais, medidas preventivas e técnicas de recuperação. Publicação CIENTEC - Boletim Técnico 25. Fundação de Ciência e Tecnologia, Porto Alegre: RS , Brasil.

FAGUNDES NETO, J. C. P. (2008). Pericias de Fachadas em Edificações - Pintura. Editora LEUD, São Paulo: SP, Brasil, p. 216

GALLETO, A.; ANDRELLO, J. M. (2013). Patologia em Fachadas com Revestimento Cerâmicos. In: IX Congresso Internacional sobre Patologia y Recuperacion de Estructuras - Cinpar. João Pessoa, Paraíba, Brasil.

PEREIRA, C. H. D. A. F. (2007). Contribuição ao estudo da fissuração, da retração e do mecanismo de descolamento do revestimento à base de argamassa. Brasília-DF, Brasil.

SILVA, A.; BRITO, J. de; GASPAR, P. L. (2011). Service life prediction model applied to natural stone wall claddings (directly adhered to the substrate). Construction and Building Materials. Elsevier. 25 (9): 3674-3684. https://doi.org/10.1016/j.conbuildmat.2011.03.064.

UEMOTO, K.L. (1988). A pintura na manutenção de edifícios. in: Tecnologia das edificações, Editora Pini, São Paulo: SP, Brasil. p.615-618.

UEMOTO, K.L. (1998). Problemas de pintura na construção civil. in: Tecnologia das edificações, Editora Pini, São Paulo: SP, Brasil, p.589- 592.

UEMOTO, K.L; AGOPYAN, V. (1997). Durabilidade de revestimentos à base de polímeros. in Workshop - Durabilidade nas Construções - UNISINOS. São Leopoldo, Rio Grande do Sul, Brasil. p. 55-63.

VERÇOZA, E. J. (1991). Patologia das Edificações. Editora Sagra, Porto Alegre, Rio Grande do Sul, Brasil. 